individuals constitute only a small minority of humanity. She addresses this question only in passing, with a whiff of group selection: "We vary in our capacity for enthusiasm, because a diversity of temperaments serves the collective good." But we know that evolution favours individual fitness, not the collective good. A more interesting story would explore the possible fitness disadvantages of optimism under some circumstances and advantages under others, leaving the population polymorphic, but Jamison doesn't really develop this possibility.

In the absence of a well worked-out model or evolutionary thesis, one is left with little more than descriptions of the exuberant lives. These are certainly vivid, but the prose often takes on a purple hue and the book is extremely repetitious. It may be my own phlegmatic temperament, but I was longing to see some sober hypotheses or experiments, and I was wearied by the constant explosion of the verbal sky-rockets: colourful, yes; eye-catching, certainly; but they tended to fizzle out and leave nothing lasting in the sky.

Daniel Nettle is in the Department of Psychology, Brain and Behaviour, University of Newcastle,

Newcastle NE1 4HH, UK.

\section{Stemming the tide of turtle extinction}

\section{Sea Turtles: A Complete Guide to their Biology, Behavior, and Conservation}

by James R. Spotila

Johns Hopkins University Press: 2004.

240 pp. $\$ 24.95$

\section{Graeme C. Hays}

Humans have a history of driving once abundant species to extinction. The passenger pigeon is thought to have once been the most abundant bird on the planet, with several billion in North America when Europeans arrived. But by the end of the nineteenth century the species had been exterminated through hunting and habitat loss. Extinctions approaching this magnitude may be under way with some sea-turtle populations. It is estimated, for example, that there were tens of millions of green turtles in the Caribbean when Columbus arrived in the fifteenth century, but human harvesting has since reduced this number by around $95 \%$. Some populations have already been driven to extinction: the last green turtles nested in Bermuda in the 1930s.

The survival of sea-turtle populations is now dependent on conservation efforts. In the late 1990s I was part of a group that travelled to Ascension Island to assess the status of the nesting green-turtle population. To

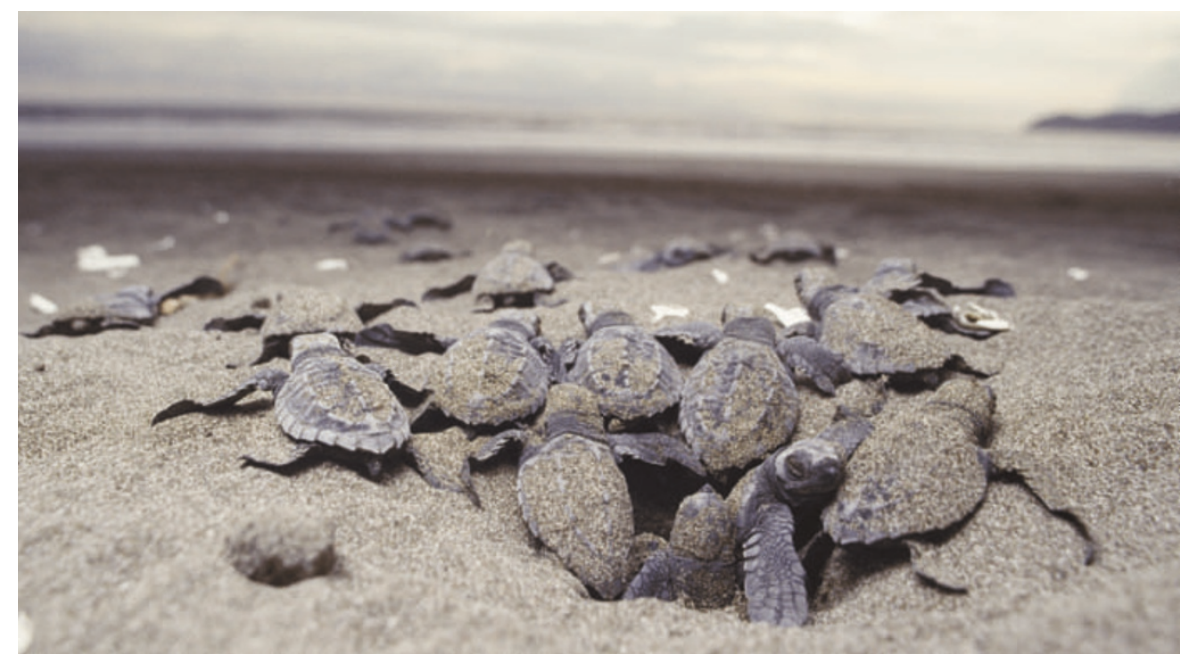

Hatching a plot: conservationists have acted to save the Kemp's ridley sea turtle from extinction.

our pleasant surprise we recorded thousands of nests each year and found that this population had grown since the previous census 20 years before, a success story reflecting conservation efforts both at Ascension Island to protect breeding turtles and in Brazil where these turtles forage. This same positive outlook has been reported elsewhere. For example, monitoring of greenturtle populations in Hawaii and Costa Rica for the past 30 years has revealed upward trends at both sites.

We can rejoice in these demonstrations of just how effective conservation measures can be: they provide living testimony that the tide of sea-turtle decline can be stemmed. But we cannot be complacent, warns Jim Spotila in his book Sea Turtles. Many sea-turtle populations continue to suffer high mortality at the hands of humans, and the spectre of population extinction still looms large.

This lavishly produced book is filled with numerous excellent photographs of sea turtles in their various habitats, as well as beautiful schematics of anatomy and distribution maps. But this is much more than just a coffee-table book: it also deserves space on the academic's bookshelf. Spotila has been a front-line turtle researcher for many years and his extensive knowledge is evident throughout, with clear descriptions of seaturtle physiology, ecology and threats to conservation. Along the way we read a fascinating account of how "perhaps the greatest zoological puzzle of the last century" was solved. I won't spoil your enjoyment by telling you more. Detailed information on the biology of each species is accompanied by case studies illustrating how beach development, collection of eggs, directed killing of turtles for their meat and shell, and incidental capture have contributed to the demise of various populations.

Often topics are covered with particular reference to Spotila's own work, giving parts of the book an autobiographical feel. The text is infused with human-interest stories and stand-alone biographies of prominent conservation workers. These personal accounts help bring the material to life, broadening the target audience compared with more specialist volumes such as the The Biology of Sea Turtles (CRC Press, 1997, 2002). Spotila describes, for example, his team's perilous first attempts to radio-track turtles from an old inflatable boat held together with duct tape. And his account of Anne Meylan's work on the diet of hawksbill turtles ends with the sad postscript of how sponge spicules embedded in her fingers led to her losing her right hand.

Although the book is generally up to date, I felt more could have been done to enthuse readers about how the past decade has seen technology (for example, satellite tracking and depth-recording devices) revolutionize our understanding of the free-living behaviour of sea turtles. In the main, only early work in this area by Spotila's own group is covered in detail. Also, at times one is left with a forlorn view of the prospects for sea-turtle survival. For example, leatherback turtles face the gauntlet of literally millions of hooks deployed each day on longlines set for tuna and swordfish. Spotila describes how the search for an answer to this problem "is going slowly", but there is important recent work showing how changing hook and bait types can greatly reduce turtle bycatch without affecting the catch of target species.

In general the book gives far more space to conservation concerns than to conservation successes, but it is success stories that inspire the legions of conservation workers around the world by showing that their efforts can reap dividends. These are small criticisms, however. This beautifully produced book deserves to be widely read to achieve its main aim of alerting people to the many threats facing sea turtles.

Graeme C. Hays is in the Department of Biological Sciences, Institute of Environmental Sustainability, University of Wales Swansea, Swansea SA2 8PP, UK. 